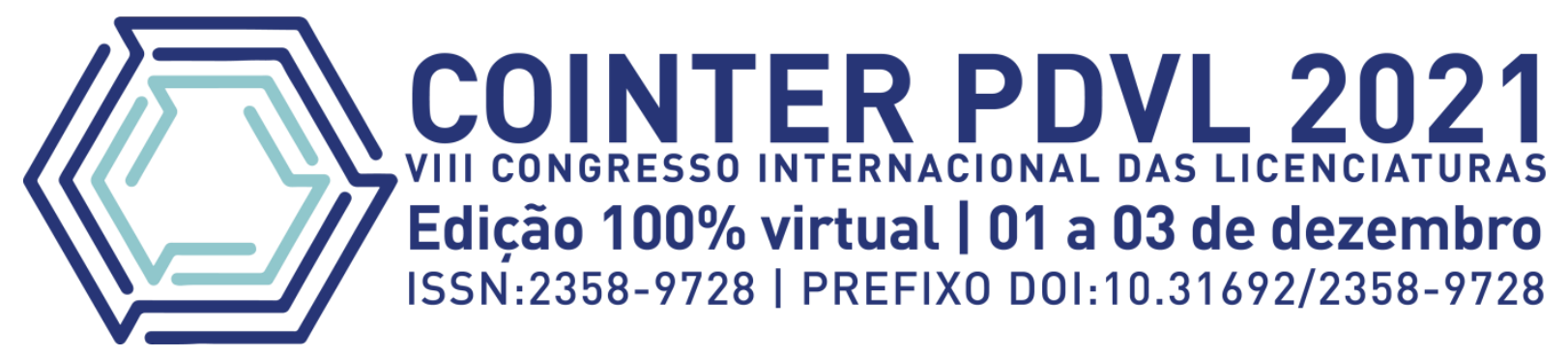

\title{
ATIVIDADES LÚDICAS PARA O ENSINO DE BIOLOGIA EM UMA ESCOLA PÚBLICA PERNAMBUCANA
}

\section{ACTIVIDADES DE JUEGO PARA LA ENSEÑANZA DE BIOLOGÍA EN UNA ESCUELA PUBLICA DE PERNAMBUCANA \\ FUN ACTIVITIES FOR TEACHING BIOLOGY IN A PUBLIC SCHOOL IN PERNAMBUCANA}

\author{
Apresentação: Comunicação Oral \\ Vitória Regina Freire Clementino Gomes de Carvalho ${ }^{1}$; Matheus Emanoel Leite Alves ${ }^{2}$; Jose Pinheiro do \\ Monte $^{3}$; Aretuza Bezerra Brito Ramos ${ }^{4}$; Dan Vitor Vieira Braga ${ }^{5}$
}

DOI: https://doi.org/10.31692/2526-7701.VIIICOINTERPDVL.0260

\begin{abstract}
RESUMO
A ludicidade é um meio que cada vez mais está crescendo no dia a dia, podendo ser um grande aliado na área do ensino médio, principalmente para lecionar os conteúdos de Biologia. Assim, o lúdico pode ser utilizado como promotor da aprendizagem, nas práticas escolares, possibilitando a aproximação dos alunos com o conhecimento. Porém, devem ter sempre claros os objetivos que se pretende atingir com a atividade lúdica que vai ser utilizada, devendo respeitar o nível de desenvolvimento em que se encontra o estudante, assim como o tempo de duração da atividade. Nesse sentido, o presente artigo teve como objetivo desenvolver atividades lúdicas voltadas para o ensino de Biologia em uma escola pública do Sertão Pernambucano, visando auxiliar no processo de ensino-aprendizagem dos estudantes do ensino médio. $\mathrm{O}$ estudo foi formulado na Escola de Referência em Ensino Médio de Salgueiro, especificamente nas turmas do $3^{\circ}$ Ano. Para a formulação do estudo foi realizado as etapas de ambientação e imersão na escola campo, sendo especificamente, a segunda fase composta por ferramentas lúdicas que foram elaboradas e apresentadas aos alunos. As ferramentas de ensino foram desenvolvidas com intuito de busca um maior aprofundamento nos conhecimentos dos conteúdos direcionados à Biologia, assim como ajudar os docentes da área a conseguiram ter uma maior base metodológica que possa aplicar com os seus alunos. Desta forma, o mais indicado seria ter o uso das ferramentas lúdicas com mais intensidade e assim transmitir um conhecimento mais prazeroso ao discente e criar um elo de ligação entre aluno e professor. Assim transmitia um ambiente escolar mais descontraído e mais excêntrico para o aluno e conseguiria fazer com que despertasse mais um conhecimento da parte dos discentes. Os fatos relevantes apresentados a partir desse estudo, permitiu observar que o lúdico trabalhado em sala de aula poderá fixar a atenção dos discentes, sendo os jogos, ou seja, a ludicidade a maneira fácil de unir o útil ao agradável, fazendo com que os discentes despertem mais do seu conhecimento.
\end{abstract}

Palavras-Chave: Ludicidade, Aprendizagem, Docente.

\footnotetext{
${ }^{1}$ Licenciatura em Ciências Biológicas, FACHUSC, vitoria.carvalho@ fachusc.com

${ }^{2}$ Ciências Biológicas, FACHUSC, matheus.alves@ fachusc.com

${ }^{3}$ Ciências Biológicas, FACHUSC, pinheirodumonte@ hotmail.com

${ }^{4}$ Ciências Biológicas, FACHUSC, aretuza.ramos@ fachusc.com

${ }^{5}$ Mestre em Gestão e Políticas Ambientais, FACHUSC, dan.braga@ fachusc.com
} 


\section{RESUMEN}

La alegría es un medio que crece cada día más, y puede ser un gran aliado en el ámbito del bachillerato, especialmente para la enseñanza de contenidos de Biología. Así, lo lúdico se puede utilizar como promotor del aprendizaje en las prácticas escolares, permitiendo que los estudiantes se acerquen al conocimiento. No obstante, siempre deben tener claros los objetivos que pretenden conseguir con la actividad lúdica que se utilizará, respetando el nivel de desarrollo en el que se encuentra el alumno, así como la duración de la actividad. En este sentido, este artículo tuvo como objetivo desarrollar actividades lúdicas dirigidas a la enseñanza de la Biología en una escuela pública en el Sertão Pernambucano, con el objetivo de ayudar en el proceso de enseñanza-aprendizaje de los estudiantes de secundaria. El estudio se formuló en la Escuela de Referencia del Bachillerato Salgueiro, específicamente en las clases de 3er año. Para la formulación del estudio se llevaron a cabo las etapas de ambientación e inmersión en la escuela de campo, específicamente, la segunda fase consistió en herramientas lúdicas que fueron elaborados y presentados a los estudiantes. Las herramientas didácticas se desarrollaron con el objetivo de buscar una mayor profundización en el conocimiento de los contenidos dirigidos a la Biología, así como ayudar a los docentes del área a tener una mayor base metodológica que puedan aplicar con sus alumnos. Así, lo más adecuado sería utilizar las herramientas lúdicas de forma más intensa y así transmitir conocimientos más placenteros al alumno y crear un vínculo entre alumno y profesor. Por lo tanto, transmitió un ambiente escolar más relajado y excéntrico para el estudiante y podría despertar más conocimiento de los estudiantes. Los hechos relevantes presentados a partir de este estudio, permitieron observar que lo lúdico trabajado en el aula puede fijar la atención de los estudiantes, con el juego, es decir, la lúdica la manera fácil de combinar lo útil con lo placentero, haciendo que los estudiantes despierten más de su conocimiento.

Palabras Clave: Alegría, Aprendizaje, Maestro.

\section{ABSTRACT}

Playfulness is a means that is growing more and more on a daily basis, and it can be a great ally in the area of high school, especially for teaching Biology contents. Thus, the playful can be used as a promoter of learning in school practices, enabling students to get closer to knowledge. However, they must always have cleared the objectives that they intend to achieve with the playful activity that will be used, respecting the level of development in which the student is, as well as the duration of the activity. In this sense, this article aimed to develop playful activities aimed at teaching Biology in a public school in the Sertão Pernambucano, aiming to assist in the teaching-learning process of high school students. The study was formulated at the Salgueiro High School Reference School, specifically in the 3rd year classes. For the formulation of the study, the stages of setting and immersion in the field school were carried out, specifically, the second phase consisted of playful tools that were elaborated and presented to the students. The teaching tools were developed with the aim of seeking a greater deepening in the knowledge of the contents directed to Biology, as well as helping teachers in the area to have a greater methodological base that they can apply with their students. Thus, the most appropriate would be to use recreational tools more intensely and thus transmit more pleasurable knowledge to the student and create a link between student and teacher. Thus, it conveyed a more relaxed and eccentric school environment for the student and would be able to awaken more knowledge from the students. The relevant facts presented from this study, allowed to observe that the playful worked in the classroom can fix the students' attention, with games, that is, playfulness the easy way to combine the useful with the pleasant, making the students awaken more of your knowledge.

Keywords: Playfulness, Learning, Teacher.

\section{INTRODUÇÃO}

De acordo com sua origem latina, a palavra lúdico corresponde a ludus e significa

jogo. O termo se relaciona ao brincar e essa ação normalmente é compreendida através da 
utilização dos brinquedos, dos jogos e das brincadeiras (RAU, 2011). Conforme Fortuna (2000), jogo é o suporte da brincadeira, que por sua vez, é o lúdico em ação.

Luckesi (2000) afirma que o lúdico corresponde "aquelas atividades que propiciam uma experiência de plenitude", em que é possível envolver-se por inteiro. Para Santin (1994), "são ações vividas e sentidas, não definíveis por palavras, mas compreendidas pela fruição, povoadas pela fantasia, pela imaginação" e que se articulam. Assim, elas não são encontradas nos prazeres estereotipados, no que é dado pronto, pois, estes não possuem a marca da singularidade do sujeito que as vivencia.

$\mathrm{Na}$ atividade lúdica, o que importa não é apenas o produto da atividade, o que dela resulta, mas a própria ação, o momento vivido. Possibilita a quem a vivencia, momentos de encontro consigo e com o outro, momentos de fantasia e de realidade, de ressignificação e percepção, autoconhecimento e conhecimento do outro, de cuidar de si e olhar para o outro, momentos que permitem a totalidade no processo do aprender (SILVA, 2011).

Machado (1966), ressalta que o jogo não é somente um tipo de interação, mas sim, uma atividade que tem como traço fundamental os papéis sociais e as ações em estreita ligação funcional com as motivações e o aspecto propriamente técnico-operativo da atividade. Dessa forma, destaca o papel fundamental das relações humanas que envolvem os jogos.

Entender o papel do jogo nessa relação afetiva-emocional e também de aprendizagem requer estudos de caráter psicológico, como mecanismos mais complexos, como a memória, a linguagem, a atenção, a percepção e aprendizagem, como afirma Vygotsky (1984).

Elegendo a aprendizagem como processo principal do desenvolvimento humano o autor ainda acrescenta que "a zona de desenvolvimento proximal é o encontro do individual com o social, sendo a concepção de desenvolvimento abordada não como processo interno da criança, mas como resultante da sua inserção em atividades socialmente compartilhadas com outros".

A formação lúdica possibilita ao educador conhecer-se como pessoa, saber de suas possibilidades, desbloquear resistências e ter uma visão clara sobre a importância do jogo e do brinquedo para a vida da criança, do jovem e do adulto (SANTOS, 1997; KISHIMOTO, 1999). Assim, o lúdico pode ser utilizado como promotor da aprendizagem, nas práticas escolares, possibilitando a aproximação dos alunos com o conhecimento. Porém, devem ter sempre claros os objetivos que se pretende atingir com a atividade lúdica que vai ser utilizada, devendo respeitar o nível de desenvolvimento em que o aluno se encontra e o tempo de duração da atividade (SOARES et al., 2014).

Nesta direção, compete sinalizar que o jogo nem sempre foi visto como didático, pois 


\section{ATIVIDADES LÚDICAS PARA O ENSINO DE BIOLOGIA}

como a ideia de jogo encontra-se associada ao prazer, ele era tido como pouco importante para a formação da criança (CAMPOS; BARTOLOTO; FELÍCIO, 2008).

Ferrari, Savenhago e Treviosl (2014) acreditam que por sua vez "o professor precisa estar consciente do papel do lúdico no processo de ensino-aprendizagem e que o brincar demanda planejamento e delimitação de objetivos", pois o docente pode usar a brincadeira como método de ensino que permite cumprir com os propósitos traçados para aquela aula.

Marinho et al., (2007), acrescentam que também é possível avaliar que a ludicidade não se insere nas questões educativas apenas como um passatempo, uma vez que a sua função se apresenta além desta visão, ou seja, auxilia diretamente na construção do saber.

Nesse sentido, Ferrari, Savenhago e Trevisol (2014), apresentam o fato de que o lúdico é parte contribuinte do processo de aprendizagem, e que "muitos professores sabem disso, mas outros necessitam compreender melhor sobre como tornar sua prática mais eficiente e lúdica".

Assim, baseado no exposto, o presente artigo teve como objetivo desenvolver atividades lúdicas voltadas para o ensino de Biologia em uma escola pública do Sertão Pernambucano, visando auxiliar no processo de ensino-aprendizagem dos estudantes do ensino médio.

\section{FUNDAMENTAÇÃO TEÓRICA}

Para aprender "é indispensável que haja um clima e um ambiente adequados, constituídos por um marco de relações em que predominem a aceitação, a confiança, o respeito mútuo e a sinceridade" (ZABALA, 1998). Além disso, a motivação do aluno é um aspecto importante a ser considerado para o sucesso da aprendizagem e para o envolvimento com o processo educacional, podendo ser considerada como fator decisivo do êxito e da qualidade da aprendizagem escolar (BZUNECK, 2004).

Segundo Seniciato e Cavassan (2004),

em uma aula tradicional sobre a importância da árvore para a natureza, por exemplo, parte-se do pressuposto de que a aprendizagem decorre de aspectos estritamente racionais, como a descrição, a quantificação e a qualificação abstrata da realidade, ao mesmo tempo em que atribui importância bem menor a aspectos subjetivos, como as emoções e as sensações.

Os autores ainda complementam abordando que situações como aulas em campo favorecem uma abordagem mais complexa de conteúdos e, ao mesmo tempo, menos abstrata dos fenômenos estudados, além de envolver aspectos emocionais que podem ser importantes para a motivação para a aprendizagem.

Assim, a motivação torna-se um processo psicológico que permite a interação das 
características ambientais e de atributos de personalidade, tais como motivos, razões, habilidades, interesses, expectativas, perspectiva e etc., que pode sofrer modificações, sendo o professor um fator importante (LENS; MATOS; VANTEENKISTE, 2008). Fazenda (1994) e Masetto (1992) complementa que a sala de aula deve ser um ambiente em que o autoritarismo precisa dar lugar a liberdade de expressão, a atitude interdisciplinar, podendo as aulas ocorrer com vivacidade e num ambiente de inter-relação e convivência.

Segundo Snyders (1988), o despertar para o valor dos conteúdos das temáticas trabalhadas é que fazem com que o sujeito aprendiz tenha prazer em aprender. Conteúdos estes despertados pelo prazer de querer saber e conhecer.

Portanto, o educador comprometido com seu trabalho educacional deve perceber a ludicidade na educação como uma ferramenta que facilita e qualifica o processo pedagógico, fazendo com que a aprendizagem seja significativa para o educando. Precisa buscar dentro de si a sua criança interior, às vezes adormecida, para conscientizar-se da importância da ludicidade na infância e conseguir atuar ludicamente, fomentando, nas tarefas com os alunos, a expectativa, o desafio, a curiosidade, o bom humor, o contentamento e o prazer. Do mesmo modo, o educador deve participar das brincadeiras, interagindo, demonstrando que se importa com elas, tecendo a convivência saudável de afeto, de amizade e de cumplicidade com o grupo (MARTINS, 2010).

Fortuna (2000) esclarece que, quando se emprega "no mundo do faz-de-conta um outro senso de realidade é experimentado", permitindo que haja impulso na confiança "na possibilidade de transformação da realidade marcada por novo imaginário, novos princípios e novos valores gerados na solidariedade, ousadia e autonomia" que as atividades lúdicas podem conter.

Entretanto, o ensino de Ciências nas escolas, apesar da sua importância, vem ao logo dos tempos, acontecendo de maneira fragmentada e descontextualizada (SOARES et al., 2014). No contexto da Biologia, segundo os pressupostos dos Parâmetros Curriculares Nacionais (BRASIL, 1998), a aprendizagem deve estar vinculada a ações que caracterizam o aluno como um ser pensante, que experimenta, analisa as situações e desenvolve um senso crítico a respeito das soluções encontradas.

No estudo desenvolvido por Kato e Kawasaki (2011), foi possível concluir que as concepções de contextualização do ensino mais presentes nos documentos curriculares se encontram na categoria "cotidiano do aluno", onde estes relacionam o conteúdo da disciplina à realidade, à cidadania, ao mundo do trabalho e às experiências pessoais e sociais.

A aptidão dos alunos de pesquisar, de buscar informações, abalizá-las e selecioná-las, 


\section{ATIVIDADES LÚDICAS PARA O ENSINO DE BIOLOGIA}

além da capacidade de aprender, criar, formular, ao invés de um simples exercício de memorização, deve estar presente no aluno, devendo o mesmo ser capaz de formular questões, diagnosticar e propor soluções para problemas reais (BRASIL, 1998).

Com relação ao ensino de Biologia, ele deve, ainda, colocar em prática, conceitos, procedimentos e atitudes desenvolvidas na escola, aceitando-se que, muitas vezes, o aluno sabe muito sobre um determinado conceito biológico e possui argumentos perceptivos sobre as situações, adquiridos com suas experiências, mas pode faltar a ele uma rede conceitual que lhe ofereça unidade a todos os fragmentos de informações que possui. À medida que progride nos estudos ele passa dos argumentos perceptivos aos conceituais, realizando raciocínios e analogias concretas, por meio de sua interação com o mundo e as pessoas com que tem contato. Nesse contexto, é possível dizer que a ferramenta lúdica não é o fim, mas o eixo que conduz a um conteúdo didático específico, resultando em um empréstimo da ação lúdica para a aquisição de informações (KISHIMOTO, 1996).

Assim, a educação escolar deveria extrapolar os limites da sala de aula, integrar-se as experiências por elas vividas em seu meio social. Deveria favorecer ao máximo a autoexpressão e sua participação em atividades cooperativas, as quais lhes proporcionam a oportunidade de envolver-se no trabalho partilhado e em atividades de decisão coletiva, básicos para seu desenvolvimento (FREINET, 1975). O educador quando se encontra com dificuldades em relação a disciplina, pode então trabalhar a realidade ou até mesmo transpor a aula para o pátio escolar, permitindo assim a mudança no pensamento do estudante, mas para isso o professor deve usar sua imaginação, assim como a criança usa a sua para construir o real (ANDRADE, 2012).

\section{METODOLOGIA}

A presente pesquisa é de caráter qualitativo, etnográfico e foi realizada na Escola de Referência em Ensino Médio de Salgueiro (EREMSAL), situada na cidade de Salgueiro-PE. O município fica a cerca de $520 \mathrm{Km}$ da capital Recife, localizada bem no centro do Sertão e é um polo de acesso a outras cidades. Vale salientar que, segundo Godoy (1995), a pesquisa qualitativa tem como preocupação fundamental o estudo e a análise do mundo empírico em seu ambiente natural.

Assim, o estudo foi compreendido em duas etapas, uma constituída pela ambientação escolar, que ocorreu no mês de maio do corrente ano; e a segunda realizada na sequência onde ocorreram as intervenções durante o período de dois meses. $\mathrm{Na}$ ambientação foram observados aspectos relacionados à estrutura escolar como um todo, além da didática adotada 
pelo professor durante as aulas de Biologia.

Logo após essa fase, foram realizadas duas ferramentas de intervenção por meio de atividades lúdicas, sendo uma virtual e outra presencial. Vale salientar que, as aulas estavam ocorrendo no modo presencial, seguindo os protocolos de biossegurança instituídos devido à pandemia provocada pela Covid-19, mas também de forma remota através de videoconferências no Google Meet ${ }^{\circledR}$.

Assim, a primeira ferramenta foi desenvolvida através do site Wordwall, onde atividades podem ser geradas e o link de acesso compartilhado com os estudantes. Entretanto, inicialmente foi pesquisado sobre o conteúdo de Genética, que foi abordado na atividade, e em seguida uma roleta com as perguntas foi elaborada, para que a medida que a mesma fosse sendo girada, a pergunta que saísse o aluno responderia, caso a resposta estivesse correta o aluno iria acumulando pontos, até que no fim ganharia a premiação estabelecida.

Para a segunda atividade foi desenvolvida manualmente uma ferramenta lúdica, sendo sua confecção possível a partir de uma caixa de papelão e emborrachado. Foram impressos números de um a vinte, onde na sala de aula o aluno sorteou e de acordo com a numeração ele respondeu à pergunta que correspondia aquele determinado número.

Antes de começar as ferramentas foram desenvolvidas avaliações diagnósticas denominadas neste trabalho por pré-testes, para avaliar o nível de conhecimento do aluno sobre o assunto abordado; e, ao fim da ferramenta foram submetidos ao pós-testes, para assim identificar o resultado do trabalho lúdico e também saber o que os discentes acharam do método de aprendizagem adotado.

Vale salientar, ainda, que esta pesquisa contou com o fomento da Coordenação de Aperfeiçoamento de Pessoal do Ensino Superior (CAPES), através do Programa Institucional de Bolsa de Iniciação à Docência (Pibid).

\section{RESULTADOS E DISCUSSÃO}

A aplicação da ferramenta lúdica nas turmas de $3^{\circ}$ Ano do ensino médio teve como ideia principal fazer com que o aluno entendesse melhor assuntos relacionados à Genética, sendo esse propósito alcançado tomando como base a participação durante a execução das mesmas, bem como após a aplicação do pré e pós-teste.

A roleta digital foi desenvolvida para abordar o sistema digestório (Figura 01), havendo a participação e interação dos estudantes durante a sua aplicação. Essa ferramenta lúdica também possibilitou o incremento no conhecimento do assunto, percebido através da comparação do pré e pós-teste, havendo ganhos significativos na aprendizagem. 


\section{ATIVIDADES LÚDICAS PARA O ENSINO DE BIOLOGIA}

Figura 01: Aplicação da ferramenta lúdica "Roleta digital" nas turmas da Escola de Referência em Ensino Médio de Salgueiro, PE. A - Ferramenta aplicada de $3^{\circ}$ Ano B do ensino médio; B - Ferramenta aplicada de $3^{\circ}$ Ano C.

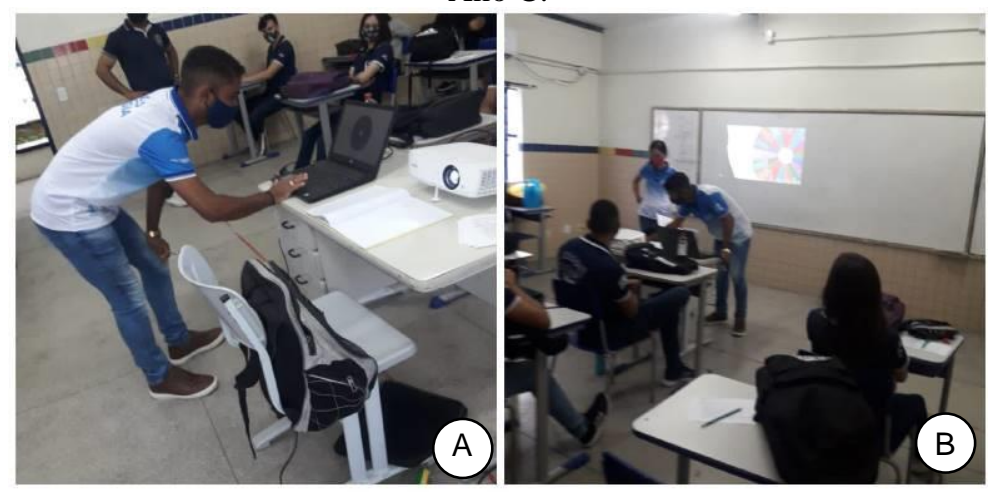

Fonte: Própria (2021).

Ressalta-se que, os discentes informaram que não tinham conhecimento sobre ludicidade, tendo em vista que muitos alunos relataram que não sabiam ou só tinham ouvido falar do lúdico. Nesse sentido, a equipe buscou levar os métodos simples e eficazes para sala de aula, mostrando que lúdico, apesar de tudo não é só brincadeira, não são só jogos, mas sim uma nova maneira de fazer com que alunos vejam o ensino.

Por meio da brincadeira a crianças ou adolescentes envolve-se no jogo e sente a necessidade de partilhar com o outro. Ainda que em postura de adversário, a parceria é um estabelecimento de relação. Esta relação expõe as potencialidades dos participantes, afeta as emoções e põe à prova as aptidões testando limites. Brincando e jogando, o adolescente terá oportunidade de desenvolver capacidades indispensáveis a sua futura atuação profissional, tais como atenção, afetividade, o hábito de permanecer concentrado e outras habilidades perceptuais psicomotoras. Brincando a criança/adolescente torna-se operativa (ALMEIDA, 2009).

Outrossim, foi observado que há uma boa relação entre aluno e professor, pois é visto um respeito e admiração pelo mestre da sala. Porém, vale ressaltar que o estudante não tem tanto interesse nos conteúdos abordados e que não há aplicação do lúdico na sala pelo professor, que justificou essa ausência por falta tempo durante as aulas, uma vez que a carga horária é bem curta para o docente construir essa relação lúdica. Mas, foi percebido que o docente procura ao máximo brincar com seus alunos.

Vale ressaltar que, os períodos de ambientação e imersão foram muito construtivo para a formação da equipe de licenciandos que desenvolveram as ações deste estudo, ampliando os conhecimentos para a carreira do professor/aprendiz, pois mostrou a realidade do ensino, trazendo uma nova metodologia, mostrado que não só aulas tradicionais são o suficiente e que a partir do lúdico se percebe mais o conhecimento vindo dos alunos, sendo um novo despertar 
no universitário que pensa em seguir essa carreira.

Figura 02: Aplicação da ferramenta lúdica "Caixa dos números" nas turmas da Escola de Referência em Ensino Médio de Salgueiro, PE. A - Momento de perguntas; B - Escolha do estudante para resposta; C - Sorteio dos números; D - Estudante respondendo a pergunta; E - Interação entre os participante e equipe desenvolvedora da ferramenta.

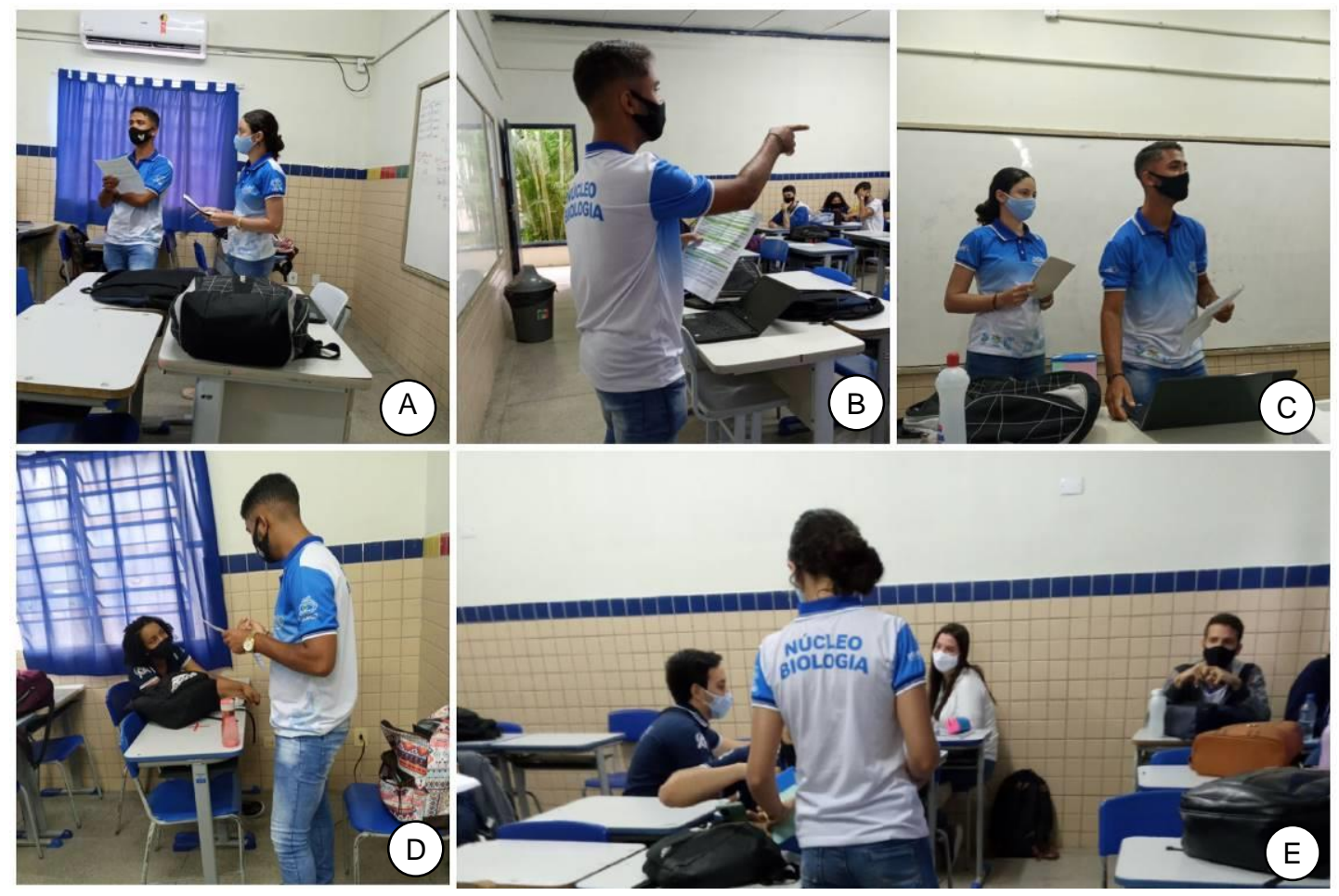

Fonte: Própria (2021).

Gomes (2017) afirma que a partir da utilização destas atividades é possível contextualizar os conteúdos e assim o aluno passa a ver sentido no que está aprendendo. Os jogos auxiliam no desenvolvimento do raciocínio logico, estimulam o pensamento independente, a criatividade e a capacidade de resolver problemas, corroborando assim com os dados observados.

Segundo Fortuna (2008), "na brincadeira somos exatamente quem somos e, ao mesmo tempo, todas as possibilidades de ser estão nela contidas. Ao brincar exercemos o direito à diferença e a sermos aceitos mesmo diferentes ou aceitos por isso mesmo."

De acordo com Luckesi (2000), a verdadeira participação em uma atividade lúdica, amplia toda experiência, para qualquer outra coisa além dessa própria atividade. Isso quer dizer que "jamais devemos perder o foco de qualquer que seja a sua atividade", devendo ser dada sua devida importância, pois é "impossível servi a dois senhores ao mesmo tempo".

A ludicidade deve ser um alvo para o ensino de Biologia e com isso torna as aulas mais atraentes para os alunos (ROSITO, 2008). Nesse mesmo contexto, Oliveira (1999) enfatiza que "ensinar ciências não se restringe a transmitir informações ou apresentar apenas um caminho, mas é ajudar o aluno a tomar consciência de si mesmo, dos outros e da 


\section{ATIVIDADES LÚDICAS PARA O ENSINO DE BIOLOGIA}

sociedade."

Por sua vez, Freitas e Aguiar (2012) compreendem que jogos usados no ambiente escolar, devem ser considerados como um aliado no processo de ensino aprendizagem. Os autores ainda complementam dizendo que "no ambiente escolar ao se falar de Jogos Pedagógicos é possível defini-los como basicamente modelos de situações reais", podendo ser um grande aliado do professor, ao lhe oportunizar à diversificação com recurso para o trabalho pedagógico em suas aulas, tornando-as mais atrativas e criativas.

Azevedo e Neves (2009), ressaltam a importância de que o lúdico seja entendido como um mundo de possibilidades e de aprendizagem no âmbito escolar. Complementando esse pensamento, Campos, Bortoloto e Felício (2008), destacam que o lúdico pode ser usado como agente de aprendizagem nas práticas escolares, e com isso possibilita uma aproximação dos alunos com o conhecimento científico.

Pinto e Tavares (2010), afirmam que as atividades lúdicas exercem um papel importante na aprendizagem, uma vez que é possível que os professores reúnam dentro da mesma situação, o lúdico e o educar. Ainda dentro desse contexto, os autores dizem que é necessário que as escolas sensibilizem no sentido de desmistificar o papel do lúdico, que não é apenas um passatempo, mas sim uma ferramenta de grande valia na aprendizagem em geral, inclusive de conteúdos, pois propõe problemas, cria situações, assume condições na interação.

Ao sentir que as vivências lúdicas podem resgatar a sensibilidade, até então adormecida, ao perceber-se vivo e pulsante, o professor/aprendiz faz brotar o inesperado, o novo e deixa cair por terra que a lógica da racionalidade extingue "o calor das paixões", dando lugar ao técnico (SANTIN, 1994), permitindo-o construir alicerçado no afeto, no poder fazer, sentir e viver.

Luckesi (2005) comenta que "[...] uma educação centrada em atividades lúdicas tem a possibilidade, de um lado, de construir um Eu (não um ego) saudável em cada um de nós, ou, por outro lado, vagarosamente, auxiliar a transformação do nosso ego constritivo num Eu saudável [...]".

Além disso, o autor menciona que uma educação lúdica tem na sua base uma compreensão de que o ser humano é um ser em movimento, permanentemente construtivo de si mesmo, fugindo assim, do entendimento de que o ser humano é um ser dado pronto e que deve, no decorrer da existência, "salvar a sua alma", visão sobre a qual está assentada a pedagogia tradicional.

Negrine (1994), por sua vez diz que as contribuições das atividades lúdicas no desenvolvimento integral indicam que elas contribuem poderosamente no desenvolvimento 
global da criança e que todas as dimensões estão intrinsecamente vinculadas: a inteligência, a afetividade, a motricidade e a sociabilidade são inseparáveis, sendo a afetividade a que constitui a energia necessária para a progressão psíquica, moral, intelectual e motriz da criança.

\section{CONCLUSÕES}

Os fatos relevantes durante a ambientação e imersão realizadas a partir desse estudo, permitiu observar que o lúdico trabalhado em sala de aula poderá fixar a atenção dos discentes, pois eles acham que aulas tradicionais precisam de um complemento, sendo os jogos, ou seja, a ludicidade a maneira fácil de unir o útil ao agradável e fazendo com que despertem mais do seu conhecimento.

O aluno percebe que o lúdico não é só uma maneira de brincar, jogar, descontrair, mais também uma maneira de mostrar o lado que muitas vezes o professor não conhece e que leva muito conteúdo, desperta muitos sentimentos bons, consequentemente a aprendizagem.

\section{REFERÊNCIAS}

ANDRADE, S. S. O lúdico na vida e na escola: desafios metodológicos. Curitiba: Appris, 2012.

ALMEIDA, A. Ludicidade como instrumento pedagógico. v. 12, 2009.

AZEVEDO, R. O. M.; NEVES, C. O lúdico contribuindo na formação de professores da educação infantil e dos anos iniciais do ensino fundamental. - Revista ARETÉ - Revista Amazônica de Ensino de Ciências, n. 3. 2009.

BRASIL. Parâmetros Curriculares Nacionais: terceiro e quarto ciclos do ensino fundamental. Brasília; MEC/SEF, 1998.

BZUNECK, J.A. Motivar seus alunos: sempre um desafio possível. Disponível em: <http://www.unopar.br/2jepe/motivacao.pdf>. Acesso em 04 dez. 2011.

CAMPOS, L.M.L; BORTOLOTO, T.M.; FELICIO, A.K.C. A produção de jogos didáticos para o ensino de ciências e biologia: uma proposta para favorecer a aprendizagem. 2008.

CAMPOS, M.C.C; NIGRO, R.G. Didática de ciências: o ensino aprendizagem como investigação. São Paulo: FTD,1999.

FAZENDA, I. C. A Interdisciplinaridade: história, teoria e pesquisa. Campinas/SP, Papirus. 1994.

FREITAS, M. S. de; AGUIAR, G. P. de. Educação e ludicidade na primeira fase do ensino fundamental. Interdisciplinar: Revista Eletrônica da Univar. n. ${ }^{\circ}$ p. 21 - 25. 2012. 
FREINET, C. As técnicas Freinet da escola moderna. Trand. Silva Letra. 4 ed. Lisboa: Estampa, 1975.

FREIRE, P. Pedagogia da Autonomia: saberes necessários à prática educativa. São Paulo: Paz e Terra, 1996.

FERRARI, K. P. G.; SAVENHAGO, S. D.; TREVISOL, M. T. C. A contribuição da ludicidade na aprendizagem e no desenvolvimento da criança na educação infantil. Unoesc \& Ciência-ACHS, v. 5, n. 1, p. 17-22, 2014.

FORTUNA, T. R. Sala de aula é lugar de brincar? In: XAVIER, M. L. M.; DALLA; ZEN, M. I. H. (org.) Planejamento em destaque: análises menos convencionais. Porto Alegre: Mediação, 2000.

GODOY, S. A. Introdução à Pesquisa Qualitativa e Suas Possibilidades. Revista de Administração de Empresas, v. 35, n. 2, p. 57-63, 1995.

GOMES, C. S. V. O lúdico como ferramenta importante para o processo de aprendizagem na educação infantil: o professor como mediador das atividades lúdicas. Barra do Bugres: Centro de Educação à distância, curso de Pedagogia. 2017.

KATO, D. S., KAWASAKI, C. S. As concepções de contextualização do ensino em documentos curriculares oficiais e de professores de Ciências. Ciência \& Educação. V. 17; n. 1. 2011 .

KISHIMOTO, T. M. O jogo e a educação infantil. Pioneira, São Paulo, 1994.

LENS, W.; MATOS, L.; VANSTEENKISTE. Educação. Porto Alegre, v.31, n.1, p.17-20, 2008.

LUCKESI, C. C. Educação, ludicidade e prevenção das neuroses futuras: uma proposta pedagógica a partir da Biossíntese. In: LUCKESI, C. C. (org.) Ludopedagogia - Ensaios 1: Educação e Ludicidade. Salvador: Gepel, 2000.

Avaliação da Aprendizagem Escolar. 17 ed. São Paulo, SP: Cortez, 2005.

MACHADO NETO, A. L O direito e a vida social - 1930 ... 1966.

MARINHO, H. R. B. et al. Pedagogia do movimento: universo lúdico e psicomotricidade. 2.ed. - Curitiba: Ipbex, 2007.

MARTINS, M. E. O. A ludicidade na educação. 2010. Trabalho de Conclusão de Curso (Licenciatura em Pedagogia). Universidade Federal do Rio Grande do Sul. 2010.

MASETTO, M. T. Aulas vivas. São Paulo: MG Editores Associados. 1992.

NEGRINE, A. Aprendizagem e desenvolvimento infantil. Porto Alegre: Propil, 1994.

OLIVEIRA, D. L. de. Ciências nas salas de aula. Porto Alegre: Ed. Mediação, 1999. 
PINTO, C. L.; TAVARES, H. M. O lúdico na aprendizagem: apreender e aprender. Revista da Católica, Uberlândia, v. 2, n. 3, p. 226-235, 2010.

RAU, M. C. T. D. A ludicidade na educação: uma atitude pedagógica. Curitiba: Ibpex, 2011.

ROSITO, B. A. O ensino de ciências e a experimentação In: MORAES, R. (org.). Construtivismo e ensino de Ciências: reflexões epistemológicas e metodológicas. Porto Alegre: EDIPUCRS, 2008.

SANTIN, S. Educação Física: da alegria do lúdico à opressão do rendimento. Porto Alegre, RS: ESEF - UFRGS, 1994.

SANTOS, S. M. P. (Org). O lúdico na formação do educador. Petrópolis, RJ: Vozes, 1997.

SENICIATO, T; CAVASSAN, O. Aulas de Campo em ambientes naturais e aprendizagem em Ciências: um estudo com alunos do ensino Fundamental. Ciência e Educação, vol. 10, n.1, p. 133-147, 2004.

SILVA, A. G. da. Concepção de lúdico dos professores de Educação Física Infantil. Londrina: Universidade Estadual de Londrina. 2011.

SNYDERS.G. La Joie à L`école. Paris: PUF. 1996.

SOARES, M. C.; LANES, K. G.; LANES, D. V. C.; LARA, S.; COPETTI, J.; FOLMER, V.; PUNTEL, R. L. O ensino de ciências por meio da ludicidade: alternativas pedagógicas para uma prática interdisciplinar. Revista Ciências \& Ideias v. 5, n.1. 2014.

SOARES, J. L. Biologia. 9.ed. São Paulo: Scipione, 1999.

VYGOTSKY, L.S. Pensamento e linguagem. São Paulo: Martins Fontes. 1984.

ZABALA, A. A prática educativa: como ensinar. Porto Alegre: Artmed, 1998. 